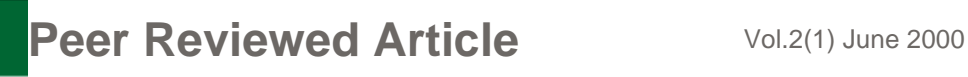

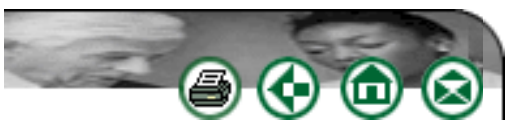

\section{How to compete in the perpetual innovation economy}

\author{
Eric Itzkin \\ eitzkin@mj.org.za
}

\begin{abstract}
Contents
Introduction

Perpetual innovation economy

Types of innovation

Beyond traditional research and development

The learning organisation

Some implications for the information profession

Conclusion

References
\end{abstract}

\section{Introduction}

New productive processes, new products or new services are the main driving force behind economic growth and development. All economies have finite physical resources like labour and capital. Without technological innovation, opportunities for expansion would eventually run out. Growth can only be sustained by generating new and better ways to use the world's limited resources.

The pace of technological innovation, together with productivity and economic growth, has been greatly speeded up in modern times. Although the Middle Ages produced a few inventions such as windmills and horseshoes, technological progress was almost imperceptible compared to more recent developments. During the nineteenth and twentieth centuries real gross domestic product (GDP) per person in the advanced economies grew by about 1.6 per cent per year on average, a rate at which income per head doubles every 44 years. Over the 13 centuries before 1800, however, real output per head crept up by an average of no more than 0.1-02 per cent a year (Woodall,1996:7). Real incomes doubled only every 500 years at this rate, while living standards did not improve noticeably during an individual's lifetime.

The recent advent of the information economy has further accelerated the pace of change, with the life cycles of both technologies and products becoming dramatically shorter. The basic economic resources in the information economy are no longer physical and capital assets, but the more intangible resources of information and knowledge. New knowledge or innovation is increasingly being applied to achieve economic results. This process of innovation can be defined as 'the application of knowledge to produce new 
While the knowledge base of an enterprise has become central as a source of competitive advantage, innovation has become absolutely crucial for ensuring that these advantages are sustained. Creative use of existing knowledge and more effective acquisition, integration and processing of new knowledge is therefore imperative. Innovative applications of knowledge open up new business opportunities at an increasing pace. But, imitation also creates new opportunities for competitors, at the expense of the original innovators, thus producing a dynamic competitive process. To survive, keep pace with change, and ultimately to challenge for dominance, enterprises are obliged to carry out continuous improvement and innovation. As the competitive process eliminates a given business opportunity, continual innovation drawing on a growing abundance of knowledge creates new opportunities.

The innovative process not only creates new knowledge, but also simultaneously renders established mindsets, technologies, practices and routines obsolete. Short periods of competitive advantage are increasingly cut across, upset, and disrupted by the appearance of new technologies and products which oust older ones.

To compete in this ever-changing environment, enterprises will have to plan abandonment, rather than try to prolong the life of a once-successful practice, policy or product.

Paradoxically, though, once-innovative enterprises often become trapped by their own success. As Tushman and Nadler (1986:75) point out, 'in one industry after another the same factors that create a successful innovative company often plant the seeds of complacency and failure as competitive conditions change'.

In other words, past success often breeds inertia and stagnation as organizations cling to their old winning formula. General Radio, which dominated the market for electronic-testequipment in the USA for over 30 years, is a case in point. While new competitors took advantage of computers, systems technology and new marketing approaches, General Radio remained committed to the technologies and practices it knew best. During the 1960s General Radio's profits and market share dropped, and it was only through a complete transformation of the company, driven by mostly new managers, that the organization was rescued (Tushman \& Nadler, 1986:74).

Initial success can easily result in a kind of tunnel vision which is focused on, and reproduces, existing activities and knowledge within an organization, with little cognitive openness to new knowledge in the environment. This bounded vision is characterized by the tendency to think and act within the routines of the organization (Johannessen, Olsen \& Olaisen, 1999:124).

Highly inertial organizations frequently fail to register awareness of environmental challenges due to organizational complacency or stunted external vigilance. If an external threat is in fact recognized the response of established organizations is often to increase their reliance on obsolete technology and to carry on 'doing what we do best'.

Past successes can thus result in a stunted ability to learn and adjust to the accelerating pace of innovation and change. Competitive advantage and innovation are inextricably linked to the ability to learn. Learning and change are two sides of the same coin. The speed-up of change confronts individuals and organizations with new problems and solving these problems requires new skills.

Increased learning and innovation becomes essential to meet the challenges of accelerating change. The innovation/learning process is characterized by cumulative circular causation. The selection by employers of more learning-oriented employees and the market selection of change-oriented firms further accelerates innovation and change (Lundvall \& Borras: 2). 


\section{Research problem}

Continuous innovation has become essential for sustained competitive advantage. This innovation has to be organized as a systematic process of continual improvement. This article identifies and discusses organizational characteristics which foster learning, innovation and renewal. It seeks to answer the following main research problem:

What are the organizational factors needed for sustained competitive advantage in the perpetual innovation economy?

To answer this question it is necessary to understand how the perpetual innovation process operates in the economy as a whole. The following sub-problem will therefore also need to be addressed:

What are the mechanisms that drive the perpetual innovation economy?

The main research problem concerns the requirements for competitive advantage at the level of an organizations. The second and final sub-problem narrows the focus to consider the role of information practitioners, looking at how they can reposition themselves so as to play a more valuable role in a dynamic and fast-changing environment:

How can information practitioners play a more central role in the perpetual information economy?

This article reviews recent research findings on innovative organizations as well as some theoretical discussions of innovation in the global economy. Much of the literature on innovative organizations has been based on a cooperative model which emphasizes the importance of learning, the value of networking and the benefits of collaboration rather than competition. As well as examining these assumptions, the report outlines the theory of the perpetual innovation economy developed by Tessa Morris-Suzuki.

\section{Perpetual innovation economy}

Widespread use of computer-based automation in production has shifted the focus of economic activity away from the making of goods and towards the production of technological innovation, according to Morris-Suzuki (1997a; 1997b). Highly automated economies place a premium on the incessant generation of new productive processes and products. This process of perpetual innovation becomes central as a competitive strategy for survival in the information economy.

Morris-Suzuki explains the growth of the information economy (which she refers to as 'information capitalism') in terms of Marx's labour theory of value. According to Marx's analysis of nineteenth century Western Europe, the productive process involves three interacting elements: a) raw materials; b) tools, machinery and auxiliary materials; and c) human labour power.

The value of the first two elements is depreciated or used up in the productive process. However, the value of the used-up portion reappears by being transferred to the finished product. Their total value is thus preserved and remains constant. Since the value is in a sense just transferred to the final product, it is described as constant capital. The last element of the manufacturing process, human labour, on the other hand, is not destroyed or depreciated as a result of the production process. Human labour has the peculiar ability to create more value than is used up in production. Because labour creates new value, Marx 
described the capital advanced to purchase labour (i.e. wages) as variable capital.

The ratio of constant and variable capital in a given productive process is referred to as the organic composition of capital. As less labour is employed in production, or more constant capital is injected, the organic composition of capital rises. Marx maintained that the rising organic composition of capital will cause the rate of profit to fall over time. The generation of profits depends on extracting value from living labour. Human labour is, in Marx's view, the sole source of surplus value (the basis of profits) and underpins the whole economy.

Capitalists compete with each other to maximize profits, and one of the main methods for achieving this is by cutting labour costs through the introduction of more efficient technology. This strategy has become particularly conspicuous with recent advances in factory automation and information technology.

Marx, however, predicted that the increasing organic composition of capital cannot be maintained indefinitely, as the value production process cannot be totally free of the human element. Since human labour power is the sole source of surplus value, total automation would not yield profits, in Marx's view.

The spread of automation causes organizations to move into information producing activities and become perpetual innovators, according to Morris-Suzuki. The industrialist who has to cut costs (primarily labour costs) so as to compete with others seems trapped in a situation where increased investments in technology yield diminishing returns. To escape the dwindling returns of investment in dead capital (machines, technology, etc.), the industrialist shifts the thrust of surplus value creation away from the production of goods towards the production of innovation. Morris-Suzuki calls this new mode of production the perpetual innovation economy.

Increasing amounts of labour and capital are devoted to the development of new products and techniques. Automation decreases the human element in the production plant, but increases the amount of living labour in all those spheres which precede direct output. While fewer and fewer workers are engaged in physical labour, the introduction of new products causes increased demand for human labour employed in information or knowledge intensive sectors such as research and development, management, planning, administration, coordination and design. Increased employment in knowledge-based sectors of the economy supports Marx's claim that there could be no human-free production in a capitalist mode of production.

Surplus value creation can be maintained over extended periods in highly automated economies by the incessant generation of new products and new methods of production. This explains why the spread of automation has been accompanied by the 'softening' of the economy (Morris-Suzuki, 1997b:58), the process by which non-material elements such as data services and research come to constitute an ever larger share of the value of total output.

It is increasingly the innovative mental creations of knowledge workers that create value. As Kennedy (1997: 90) puts it:

'Capital can put enormous numbers of workers together in low-paid work in which mere muscle-power is exploited. However, the value generated by these workers pales in comparison to that created by knowledge workers who design a new software program or develop a new pharmaceutical'.

Morris-Suzuki (1997b:60) identifies three principal ways in which organizations shift the focus of their operations towards the production of new knowledge:

- As companies increasingly automate production, they relocate their human workforce 
to such areas as research and planning, which contribute to the production of new knowledge applied to the manufacturing of goods. In this case the business does not directly sell information as a commodity, but uses information to add value to the products it produces.

- A growing number of firms specialize in the production and sale of producer information, that is the production of software, databases and designs which will be used by other firms in their production processes.

- An expanding number of companies are also engaged in the production and sale of consumer information such as home computer software.

In a perpetual innovation economy, information or knowledge embedded in commodities, not the physical material from which they are made, becomes the main source of value. However, because of the peculiar characteristics of information products, privately owned knowledge tends to flow back into the public domain. Knowledge, once produced, can be copied and transmitted at very low cost; it is not consumed or depleted after use; moreover, the nature of knowledge is such that it is extremely difficult, if not impossible, to maintain monopolies of information indefinitely. Thus, unless the cycle of producing new knowledge applied to innovative productive techniques and products is continually repeated, knowledge used to produce advanced products will fall into the hands of competitors, leading to a fall in profits. As once exclusive information seeps back into the expanding pool of social knowledge, the pressure of competition necessitates a new wave of knowledge creation.

Product life-cycles are becoming much shorter as a result of this accelerating pressure to innovate. Hewlett Packard provides an example of this process by which the lifetimes of products become shorter and shorter. During the 1980s 70 per cent of Hewlett Packard's orders came from products less than three years old, but in the 1990s that changed to products less than two years old (Kennedy, 1997:92). Whereas the obsolescence of industrial equipment was formerly measured in decades, rapid change, especially in electronics, is now affecting all products.

\section{Perpetual learning economy}

Kennedy (1997:97), following on from Morris-Suzuki's work, points out that innovationgenerating workplaces are being reconceptualized and reorganized as learning environments. The traditional model of the workplace or factory as a facility to reproduce blueprints has been abandoned. In information economies production is managed in a 'knowledge factory' which continuously harnesses human creativity.

The fundamental unit in a creative learning and innovation environment is the team or social group. The principle of managing work as a social or collective process has been implemented with great success, particularly in Japan. Team-work becomes the key to continuous improvement, in striking contrast to the old management techniques of Fordism and Taylorism in which the work process was fragmented into individual efforts.

\section{Types of innovation}

Although innovation is often associated with dramatic breakthroughs in technology, most successful innovations are achieved by combining existing ideas, methods or techniques creatively, or are based on the cumulative effect of incremental changes to products and processes.

At the most basic level, there are two kinds of innovation: product innovation, or changes to 
the products a business makes or the services it supplies; and process innovation, which involves changes to the way in which products and services are made or delivered. Within each of these basic categories, there are three degrees of innovation: incremental, synthetic and discontinuous (Tushman \& Nadler, 1996).

In both product and process innovation, the greater the degree of change, the greater the required learning for individuals and organizations. As organizations move from incremental to discontinuous innovation, it becomes increasingly important for organizations to function as effective learning systems.

\section{Product innovation}

Most product innovations are incremental changes which provide new versions, added features or extensions to an otherwise standard product line. These incremental innovations occur frequently, and a large number of these changes can add up to a significant competitive advantage.

The second category of product innovation, synthetic, relates to the combination of existing knowledge in creative ways to produce significantly new products. The DC- 3 aeroplane, for instance, did not require any new technology. But through incorporating existing aeroplane innovations, it was possible to produce an aeroplane which combined size, speed and efficiency, setting the standard in its product class (at least until the next major product innovation came along).

The third type, discontinuous product innovations, involves the development or application of significant new technologies, such as the change from steam to diesel locomotives. Such major innovations require new skills and processes, necessitating a complete transformation in organizations moving away from an obsolete product technology.

\section{Process innovation}

Process innovations alter the way the product is manufactured or the service provided. These innovations may be invisible to the user except for changes in the cost or quality of the product. As with product innovation, most process innovations are incremental improvements which result in better quality, lower costs or both. Synthetic process innovations can improve existing production processes, making them faster, more efficient and able to handle greater volumes. Discontinuous process innovations introduce completely new ways of producing products or services, such as the use of robots and automation in vehicle manufacturing plants.

\section{Shifting role of product and process innovation}

Both process and product innovation are important, but their relative importance shifts during the course of the product life cycle. The emphasis falls on product innovation during the introductory stage, as several forms of the same product compete for dominance. During the early phases of the motor-car for example, at least four engine types (internal combustion, steam-powered, battery and wood) competed for the relatively small market. This stage of major product variation leads to the emergence of a dominant design, representing the industry standard for a given product class.

During the next stage of a product life cycle, major product competition gives way to competition based on quality, price and segmentation. In other words, process innovation becomes more pronounced than product innovation. The rate of innovation then slows down during the mature stage in the product life cycle, when only incremental product and process 
innovation are possible. This mature phase continues until the next wave of major product innovation.

Because of the way in which innovation shifts over time, organizations need to be dynamic, flexible and responsive to changing conditions. Balancing short term and long term needs is crucial for effectively managing innovation. To master both product and process innovation organizations need to produce effectively for the short term while making constant improvements, and also cultivating the capacity to learn for the future. Those organizations that get stuck in a single mode of operation will be incapable of switching to different kinds of innovation as product life cycles develop.

\section{Beyond traditional research and development}

Historically, in the old capital-intensive and labour-intensive organizations of the past, innovation was often generated through a series of discrete steps in research development and production. In the new knowledge-based economy, however, innovation is increasingly generated through networks, partnerships and collaboration.

The traditional Research \& Development (R\&D) departments of the past were kept separate from the organization's day-to-day operations so that they could, without interference, invent new products. This separation often divorced R\&D from internal and external information sources, and often led to external customers' needs being overlooked.

In recent years the emphasis has shifted towards wider networking that focuses on internal and external customers. One of the approaches which has recently appeared involves having skunk works within an organization (Fisher, 1999). This model combines the swing towards networking with a continued belief that creativity and innovation need to be nurtured in an environment of separateness where one can create regardless of the push and pull of day-today business.

Skunk works create an isolated, protected and somewhat cloistered environment (much like the old R\&D model) for testing innovative new ideas. The skunk work teams are protected from the pressure within the organization to produce a bottom line result until the innovation has been proven to work. What distinguishes skunk works from traditional R\&D departments is that these teams do include feedback and guidance from external and internal customers.

Other networking approaches based on the concept of the learning organization break more completely with the traditional view that innovation is a separate function in an organization. The learning organization model stresses the need for all members of an organization to become integrated in the learning and innovation process.

Innovation requires the close collaboration of $R \& D$ with other functions like production, marketing and sales. A good idea is a long way from a successful product or service, and has to be linked to production and marketing skills. As Tushman and Nadler (1986:75) explain: 'Innovation is not just R\&D; just as important are marketing, sales and production. Effective innovation requires the synthesis of market needs with technological possibility and manufacturing capabilities.'

\section{The learning organization}

Most innovative organizations are effective learning systems. Organizations that keep abreast 
of the innovation race will be those that expand their employees' capacity to learn. To excel in the innovation economy, the challenge is to build learning organizations that can cope with rapid change through continual improvement and the development of new products and services.

A learning organization facilitates knowledge creation, learning and personal development of all its employees while continuously transforming itself. Members of the organization become a community of interconnected learners committed to developing a collective intelligence.

Communication among members of the learning organization, as well as with external contacts, greatly enhances the power of learning. Learning organizations add value through contacts and communication. This can be facilitated by virtual team-networks such as intranets and extranets to help ideas flow and create new knowledge, thus building relationship knowledge (Johannessen et al., 1999:126). This relationship knowledge is dependent on internal contacts with colleagues as well as external contacts with customers, suppliers, etc.

Information-sharing and systematic collaboration have become the keys to innovation and learning. Contrary to popular folklore, new knowledge is not purely the result of individual inspiration and 'best done by loners in their garages' (Drucker, 1993:190). Rather innovation requires group problem-solving skills to harness collective expertise.

\section{Cross-boundary networking}

Because they facilitate enhanced learning, networks provide efficient organizational forms for innovation. As Fountain and Atkinson (1998:3) point out:

'Compared to large, hierarchical structures, networks more efficiently scan the environment for potentially significant events, more accurately interpret environmental change, and more creatively and adaptively craft responses to change'.

Actors in a collaborative network learn interactively. This learning is of a higher quality because it is subject to discussion and debate among knowledge workers whose backgrounds and perspectives may differ.

Organizational learning and innovation is a group and inter-group process. Individuals rarely produce ideas or solutions for complex and discontinuous innovation. Strong individual specialisation must be bolstered by team building to catalyse creativity through diversity.

The growing importance of networking, both within and between organizations, reflects the increasing complexity of the innovation process. Innovations are frequently cross disciplinary, building on disparate technologies where each technology has to combine different disciplines and organizational expertise. Nanogen, a US firm based in San Diego, for example, developed micro-electronic based disease testers in the late 1990s. The new disease testers combined expertise in micro-electronics, software, biology and chemistry (Fountain \& Atkinson, 1998:1).

To make use of his or her own knowledge, the individual knowledge worker is dependent on the specialist knowledge of other knowledge workers from diverse backgrounds

(Johannessen et al.,1999:128). Each knowledge worker needs to see how his or her branch of knowledge interacts with other branches of knowledge to function as a whole.

Since innovation involves individuals from different disciplines and departments, joint problem-solving teams within an organization can be used to bring together colleagues with experience in multiple areas. By working on common opportunities or problems, joint 
problem-solving teams drawing on expertise from across an organization can bring multiple perspective to bear and improve internal information transfer.

Those organizations where employees co-operate and communicate well internally are precisely the ones that can best collaborate with other organizations. A network culture within an organization facilitates the creation of outside networks.

Exposure to multiple information sources through external networks is essential for learning and innovation. By increasing openness to other knowledge structures in the environment, external networks can also help counteract the problem of bounded visions.

Companies routinely ask outside suppliers to develop components of an innovative product, engage in product testing, or market research and so forth. Such inter-firm cooperation need not compromise an innovating firm's ability to protect commercially important secrets. Trade secrecy and lead time would need to be carefully guarded as they can be vital to an innovator's ability to profit from an innovation. But in many instances the innovation development task which is outsourced to another firm is only a part of the whole, and revealing a part does not reveal the whole to would-be imitators (Von Hippel, 1994:437-438).

Innovation in the information economy is typically the outcome of interaction among various actors distributed between different locations and organizations. Successful innovation is increasingly taking place through the flow of ideas and technology across institutional boundaries. Electronic networks are a crucial enabling factor for the diffusion of new knowledge, by which knowledge workers can communicate outside the bounds of time and space.

The cutting edge of innovation is often at the interfaces between organizations. The focus of innovation in industry is moving away from the centralized, prestigious laboratories of large multinational corporations to large numbers of smaller and medium-sized firms in their supply chains (Fountain \& Atkinson, 1998:1). Through an expanding array of partnerships, businesses are increasingly turning to suppliers, customers and users for sources of technology and innovation.

Increased cooperation between firms is taking the form of technological alliances, consortiums and closer links between suppliers and customers. As many as 20000 inter-firm alliances were formed in the United States 1987 and 1992, compared to only 750 during the 1970s (Fountain, 1998:3). A proliferation of inter-firm networks in the form of partnerships and consortia has contributed to the successful renewal of the economy in the United States.

The fundamental reason for the rise in technology alliances between firms is that the information revolution has greatly increased the available knowledge from which new products and services can be developed. The huge array of technologies and applications has outpaced the ability of single firms to retain proficiency in the technology fields relevant to their business. The traditional pen manufacturer A.T. Cross, for instance, developed the hardware for its 'Cross Pad', a portable digital notepad, while the software was developed by IBM (Fountain \& Atkinson, 1998:3).

Corporate alliances and partnerships can also help spread the investment and risk necessary to sustain technology development and innovation. These costs have increased beyond what many single firms are able to absorb alone.

Industry research collaboration is not only in the form of one-off strategic alliances and partnerships but also through ongoing networks of learning and innovation.

These include regional, national and global networks. 
Geographic regions that include highly adaptive business networks have been termed learning regions. California's Silicon Valley is one of the most innovative learning regions. The professional culture is both highly collaborative and very competitive.

Non-proprietary technical and professional information is typically shared among companies and employees.

Despite such successes, given the high rate of change, networks that tend to be geographically closed could in some cases hamper innovation in the long run, instead of stimulating it (Lundvall \& Borras: 6). To avoid losing touch with new developments further afield, or even being locked into stagnating product areas, interaction with external contacts outside a particular area may be needed. Integrating one's organization in international networks is therefore important for making a wide spectrum of information and knowledge accessible across regional and national borders.

\section{Cultural shift}

Two distinct approaches can be used in transforming an organization's culture towards becoming a learning organization. The technological approach provides an infrastructure for communication and collaboration, typically networked computers plus software called groupware for sharing information within the organization. The traditional social approach is to work with people, concentrating on changing their understandings and practices.

Each of these approaches has critical shortcomings if introduced separately. The two approaches need to be blended to yield synergism with each other, building new learningoriented practices together with the infrastructure to support them.

Groupware tools and technology can support community-wide dialogue, creating valuable communicative support structures. This technology provides the technological infrastructure to support and reinforce new practices. But introducing the software without the necessary change towards a culture of information sharing would not be effective.

Without considerable energy and attention focused on changing the organizational culture, people find little use for technology that reflects radically new and different cultural assumptions. For example, in an organizational culture characterized by unproductive levels of secrecy, where information is doled out sparingly for maximum personal gain, tools for information sharing and collaboration will not gain wide acceptance.

The collaboration needed for innovation depends on social and cultural factors, not just on information technology. This applies not only to information sharing inside an organization but also to networks linking different organizations. It is above all trust and the norm of reciprocity to promote mutual gain that makes collaboration feasible. As Fountain and Atkinson (1998:3) argue, these shared values, or 'social capital', become a crucial enabler of innovation.

'Social capital is as important as physical capital (plant, equipment and technology) and human capital (intellect, character, education and training) in driving innovation and growth. The 'stock' of social capital is increased when a network of organizations develops the ability to work in collaboration to promote mutual productive gain. Social capital indicates those properties of an organization, notably networks, shared norms and trust, that lower the costs of coordination and cooperation and thereby increase collective productivity. Thus, well functioning partnerships, consortia, and networks are in and of themselves a form of social capital. Trust develops over time as individuals gain confidence in the reliability of others through a series of interactions. ... The norm of reciprocity is fundamental to productive relationships. Closely linked to reciprocity is the norm that actors will forego their immediate 
self-interest to act not only in the interest of the group but also in their own long-term interest'.

\section{Some implications for the information profession}

The knowledge production capability of information storage and retrieval systems can assume major economic value in the innovation-based economy. The information science community has however often overlooked this knowledge production potential. This prevents information professionals from playing a key role in the perpetual innovation economy (Karamuftouglu, 1999).

Information professionals and the information storage and retrieval systems they devise have traditionally been cast in the role of guardians and facilitators of knowledge. In this conventional framework, information retrieval is usually conceived as a process of transferring knowledge stored in databases to those who may find it useful. Traditional information retrieval work is thus mainly concerned with mechanisms that facilitate access or transfer of knowledge.

It has however become increasingly obvious that knowledge contained in large databases could also be used as a major resource for the production of new knowledge. It is for instance possible to create new knowledge by discovering new connections between a pair of documents. The fact that most innovation comes from connecting and combining existing knowledge in new patterns makes this especially significant.

To ensure that the information practitioners play a key role in innovation, it is necessary to re-conceptualize their role as producers of knowledge, as well as neutral guardians of information. The retrieval systems they devise should be re-conceptualized as tools for the production of new knowledge, as well as storage and retrieval tools (Karamuftouglu, 1999).

This requires the shift to a new paradigm of information seeking, retrieval and production as a collective and collaborative process rather than an individualistic one. Advances in network-centric computing have made the collective aspect of knowledge production highly visible. Information retrieval system designers and practitioners may find it useful to study collaborative applications developed on information networks. This can assist with the development of retrieval mechanisms that promote creativity and facilitate knowledge production as well as knowledge transfer.

\section{Conclusion}

Organizational innovation is the calculated outcome of learning opportunities. Strong communication networks within and outside the organization, providing exposure to multiple information sources, provide the essential infrastructure for nurturing learning and innovation. Sensitivity to external opportunities and internal competence provides the stimulus for organizational learning and sustained innovation.

Highly innovative organizations stress dynamic and flexible decision making. Such organizations tend to be outward-looking and self-critical, rather than overly stable and complacent. They gather diverse information regarding customers, competitors and technology, and involve multiple actors with diverse skills in processing that input. 
addition to their traditional role of acquiring, storing and distributing information, information professionals can make a significant contribution to the production of new knowledge.

Increased cooperation and information sharing between firms has emerged as an important response to intensified competition. This has taken the form of technological alliances, the formation of business networks and closer linkages between suppliers and customers. But the inclusion of some organizations in networks has, as the other side of the coin, the exclusion of other organizations which will become increasingly isolated and uncompetitive.

Sustained innovation is based on building collaborative advantage through networks and partnerships. This emerging culture of interdependence, interaction and sharing is however not reflected in traditional hierarchical management. Vertically organized firms with high levels of complacency tend towards characteristics that stunt learning and innovation.

\section{References}

Drucker, P. F. 1993. Post-capitalist society. New York, N.Y.: Harperbusiness.

Fisher, I. 1999. Innovation and creativity in the network economy. [Online]. Available WWW: http://www.4front-consulting.com/ReadingRoom/Creativity.html.

Fountain, J. E. \& Atkinson, R. D. 1998. Innovation, social capital, and the new economy. [Online]. Available WWW: http://www.dleppi.org/texts/tech/innovation.html.

Johannessen, J., Olsen, B. \& Olaisen, J. 1999. Aspects of innovation theory based on knowledge management.

International Journal of Information Management, 19: 121-139.

Karamuftouglu, M. 1999. Information retrieval and the perpetual information economy. Aslib Proceedings, 51(4): 99-108.

Kennedy, M. 1997. Value creation in the late twentieth century: the rise of the knowledge worker. In: Davis, J., Hirsch, T. \& Stack, M. (eds.) Cutting edge: technology, information, capitalism and social revolution. London: Verso, 87-102.

Lundvall, B. A. \& Borras, S. Innovation policy in the globalising learning economy. [Online] Available WWW: http://www.cordis.lu/tser/src/sumfinal.htm.

Morris-Suzuki, T. 1997a. Robots and capitalism. In: Davis, J., Hirsch, T. \& Stack, M. (eds.) Cutting edge: technology, information, capitalism and social revolution. London: Verso, 1327.

Morris-Suzuki, T. 1997b. Capitalism in the computer age. In: Davis, J., Hirsch, T. \& Stack, M. Cutting edge: technology, information, capitalism and social revolution. London: Verso, 57-71.

Tushman, M. \& Nadler, D. 1996. Organizing for innovation. California Management Review, 28 (3): 74-92.

Von Hippel, Eric. 1994. 'Sticky information' and the locus of problem solving: implications 
for innovation. Management science, 44(4): 429-439.

Woodall, Pam. 1996. A survey of the world economy. The Economist, 28 September 1996.

\section{Disclaimer}

Articles published in SAJIM are the opinions of the authors and do not necessarily reflect the opinion of the Editor, Board, Publisher, Webmaster or the Rand Afrikaans University. The user hereby waives any claim he/she/they may have or acquire against the publisher, its suppliers, licensees and sub licensees and indemnifies all said persons from any claims, lawsuits, proceedings, costs, special, incidental, consequential or indirect damages, including damages for loss of profits, loss of business or downtime arising out of or relating to the user's use of the Website.

ISSN 1560-683

Published by InterWord Communications for the Centre for Research in Web-based Applications, Rand Afrikaans University 